\title{
Effects of substituting dietary fish meal with soybean meal isolate on growth performance, digestive enzyme activity, and intestinal morphology of spotted seabass (Lateolabrax maculatus)
}

\section{Zhe Wang, Linkun Yang, Chunxiao Zhang, Xueshan Li, Ling Wang, Kangle Lu, Kai Song*}

Xiamen Key Laboratory for Feed Quality Testing and Safety Evaluation, Fisheries College of Jimei University, Xiamen 361021, China

Key words: Fish meal replacement, Soy protein isolate, Growth performance, Spotted seabass

\begin{abstract}
Soy protein isolate (SPI) is a promising plant protein source to replace fish meal (FM) in aquatic feeds. This study investigated the growth performance, digestive enzyme activity, and intestinal morphology of spotted seabass (Lateolabrax maculatus) fed diets with FM partially substituted by SPI. Three iso-nitrogenous and iso-lipidic diets were formulated to replace 0,25 , and 50\% of FM with SPI, being abbreviated as FM, SPI25, and SPI50, respectively. Each diet was allocated to triplicates of fish for 8 weeks. The results indicated that the weight gain was gradually reduced with increasing dietary SPI levels, as did intestinal trypsin and lipase activities. However, these traits were not significantly decreased until $50 \%$ of FM was substituted by SPI. Furthermore, feed intake and lipid digestibility significantly decreased with dietary SPI inclusion. Moreover, replacing $50 \%$ of dietary FM with SPI significantly reduced the intestinal villus height and perimeter ratio, whereas these traits did not markedly differ between FM and SPI25 groups. In conclusion, this study indicated that up to $25 \%$ of dietary FM could be substituted with SPI without significantly affecting the growth, digestive enzyme activity, or intestinal morphology in spotted seabass.
\end{abstract}

* Corresponding author. Kai Song. E-mail: songkai@jmu.edu.cn 


\section{Introduction}

Due to the increasing price and uncertain supply of fish meal (FM), the diet composition of carnivorous fish species is experiencing a major shift from the domination of marinederived protein to the increasing use of plant-origin ingredients (Naylor et al., 2021; NRC, 2011). Soy protein has been widely used to replace FM in aquaculture due to its favorable amino acid profile and relatively high protein content (Deng et al., 2009; Li et al., 2017). However, the major primary factor that limits the use of soy protein is the presence of multiplied anti-nutritional factors (ANFs), which usually provoke intestinal inflammatory response and growth retardation in animals (Zhang et al., 2018). As the most refined soy protein product, soy protein isolate (SPI) is produced through aqueous solubilization followed by isoelectric precipitation to eliminate most of ANFs (Deng et al., 2009; Liu et al., 2017). Due to the reduced ANFs and elevated protein $(\sim 90 \%)$ content, SPI has emerged as a promising alternative to marine protein sources in aquaculture industry.

During the past few years, several investigations have focused on the use of SPI in fish and shrimp diets, showing that SPI could partially replace FM on Florida pompano (Trachinotus carolinus), common carp (Cyprinus carpio), hybrid striped bass (Morone chrysops $\times$ M. saxatilis), and silvery-black porgy (Sparidentex hasta), etc. (Blaufuss and Trushenski, 2012; Nepal et al., 2018; Riche and Williams, 2011; Yaghoubi et al., 2016). However, the information involved in the use of SPI in spotted seabass is limited. In addition, the sensitivity to dietary plant protein inclusion is generally different from species to species, as a result of which the effects of SPI on fish physiological status and growth performance should be investigated on a case-by-case basis.

Spotted seabass (Lateolabrax maculatus) is one of the most farmed carnivorous fish in Asia. To date, the systematic study on the evaluation of replacing dietary FM with SPI for this species is lacking. Thus, the study aimed to investigate the effects of partially substituting dietary FM with SPI on growth performance, body composition, digestive enzyme activity, and intestinal morphology of spotted seabass to contribute to optimizing aquatic feedstuffs when considering the selection of optimal protein sources and their optimal proportion.

\section{Materials and Methods}

\section{Diet preparation}

The basal diet was formulated to contain $44 \%$ crude protein totally contributed by FM (FM diet), another two experimental diets were prepared with 25 (SPI25 diet) and 50\% (SPI50 diet) of FM replaced by SPI with methionine (Met) and lysine (Lys) supplemented to established requirement levels. The formulation and proximate compositions of experimental diets were present in Table 1. All ingredients were purchased from Jiakang Feed Co., Ltd. (Xiamen, China). They were ground into fine powders and thoroughly mixed in a Hobart-type mixer. After that, lipid sources including fish oil, soybean oil, lecithin, squid paste, and distilled water were separately added to the dry ingredients and thoroughly mixed again. Then, the mixed ingredients were transferred into a two-screw extrusion machine to make two sizes of pellets $(1.0 \mathrm{~mm}$ and $2.5 \mathrm{~mm})$. Diets were dried at $60^{\circ} \mathrm{C}$ for $8 \mathrm{~h}$ until an approximately $10 \%$ moisture content was reached, and then stored at $-20^{\circ} \mathrm{C}$.

\section{Feeding trial}

This study was approved by the Animal Ethical Committee of Jimei University (Xiamen, China). Spotted seabass juveniles were purchased from a commercial hatchery (Zhangzhou, China) and transferred to the indoor recirculating system at Jimei University. All juveniles were fed with the basal diet for two weeks to adapt to the experimental conditions. After the acclimation period, a total of 225 fish with similar initial weight (8.75 $\pm 0.20 \mathrm{~g}$ ) were assigned into nine $20-\mathrm{L}$ tanks ( 25 fish per tank). Experimental fish were randomly allocated to triplicates per treatment and hand-fed to apparent satiation twice daily ( $8: 00$ and $18: 00 \mathrm{~h}$ ) for 56 days. Approximately $35 \%$ of freshwater was renewed daily, and feces within each tank were collected over the last two weeks for analyzing 
digestibility. During the feeding trial, the water temperature was maintained at $27.0 \pm$ $1.0^{\circ} \mathrm{C}$ by dual air-conditioning units. The dissolved oxygen content was approximately 8.0 $\mathrm{mg} / \mathrm{L}$, ammonia nitrogen was lower than $0.1 \mathrm{mg} / \mathrm{L}$, water $\mathrm{pH}$ was 7.5-8.5, and a $12 \mathrm{~h}$ light$12 \mathrm{~h}$ dark photoperiod was adopted.

Table 1 Formulation and proximate composition of the experimental diets.

\begin{tabular}{|c|c|c|c|}
\hline \multirow[t]{2}{*}{ Ingredients (dry weight, \%) } & \multicolumn{3}{|c|}{ Diet designation } \\
\hline & $\mathrm{FM}$ & SPI25 & SPI50 \\
\hline Brown fish meal & 30.00 & 22.50 & 15.00 \\
\hline Soy protein isolated & 0.00 & 6.00 & 12.00 \\
\hline Wheat flour & 31.24 & 32.17 & 32.99 \\
\hline Wheat gluten & 13.00 & 13.00 & 13.00 \\
\hline Poultry by-product meal & 8.00 & 8.00 & 8.00 \\
\hline Fish oil & 2.00 & 2.40 & 2.90 \\
\hline Soybean oil & 2.50 & 2.50 & 2.50 \\
\hline Lecithin & 2.00 & 2.00 & 2.00 \\
\hline Squid paste & 2.00 & 2.00 & 2.00 \\
\hline Microcrystalline cellulose & 5.00 & 5.00 & 5.00 \\
\hline Vitamin C & 0.05 & 0.05 & 0.05 \\
\hline Monocalcium phosphate & 2.00 & 2.00 & 2.00 \\
\hline DL-Methionine & 0.32 & 0.42 & 0.53 \\
\hline Lysine monohydrochloride & 0.49 & 0.56 & 0.63 \\
\hline Choline chloride & 0.50 & 0.50 & 0.50 \\
\hline Mineral premix ${ }^{a}$ & 0.50 & 0.50 & 0.50 \\
\hline Vitamin premix ${ }^{b}$ & 0.30 & 0.30 & 0.30 \\
\hline $\mathrm{Y}_{2} \mathrm{O}_{3}$ & 0.10 & 0.10 & 0.10 \\
\hline \multicolumn{4}{|l|}{ Proximate compositions } \\
\hline Crude protein & 43.68 & 43.74 & 43.97 \\
\hline Crude lipid & 11.07 & 11.21 & 11.29 \\
\hline
\end{tabular}

a, b Mineral premix and vitamin premix were prepared as our recent work (Cheng et al., 2021).

\section{Sample collection}

At the termination of the feeding trial, fish in each tank were individually weighted and counted after fasting for $24 \mathrm{~h}$. Three fish per tank were randomly sampled for analysis of body composition. Twelve fish per tank were anesthetized with eugenol (1: 10000) to determine body weight and length for weight gain and condition factor analyses. After that, liver, visceral mass, and intraperitoneal fat were separately sampled and weighted for calculating body condition indices. In addition, distal intestines of two fish in each tank were sampled and fixed into Bouin's fluid for histology analysis. For enzyme activity analyses, the mid intestine samples of three fish per tank were sampled and placed into liquid nitrogen. 
Proximate analysis

Proximate compositions of fish bodies, experimental diets, and feces samples were determined according to AOAC (2002). Dumas method $(N \times 6.25)$ was adopted for crude protein analysis. Crude lipid was determined by the Soxhlet extraction method. Ash content was analyzed by combustion method at $550^{\circ} \mathrm{C}$ for $8 \mathrm{~h}$. Samples were oven-dried at $105^{\circ} \mathrm{C}$ to constant weight for determining moisture content. The yttrium contents in the diets and feces were separately quantified by inductively coupled plasma atomic emission spectroscopy (ICP-OES, Leeman, USA).

\section{Digestive enzyme}

Intestine samples were homogenized in phosphate-buffered saline (PBS). After centrifugation $\left(4000 \times g, 10 \mathrm{~min}, 4^{\circ} \mathrm{C}\right)$, the supernatant was collected and stored at $-80^{\circ} \mathrm{C}$. The activities of digestive enzymes, including trypsin, lipase, and amylase, were respectively assayed using standard assays kits (Nanjing Jiancheng Biological Company, China).

\section{Histology analysis}

Intestine sections with hematoxylin\&eosin staining were performed by Service Biotechnology Co., Ltd. (Wuhan, China) according to standard histological procedures. Micrographs were observed with a light microscope (Leica DM5500B, Germany), and morphometric analyses were conducted using image software to determine villus height/width, muscular thickness, and perimeter ratio ( $P R=$ (internal perimeter of the intestine lumen) / (the external perimeter of the intestine)) (Dimitroglou et al., 2009).

\section{Calculation and statistical analysis}

Weight gain $(W G, \%)=\left(W_{f}-W_{i}\right) / W_{i} \times 100$

Feed efficiency $(F E)=\left(W_{f}-W_{i}\right) / W_{D}$

Feed intake $(\mathrm{FI}, \mathrm{g} / \mathrm{fish})=\mathrm{W}_{\mathrm{D}} / \mathrm{N}_{\mathrm{f}}$

Survival $(\%)=\mathrm{N}_{\mathrm{f}} / \mathrm{N}_{\mathrm{i}} \times 100$

Hepatosomatic index $(\mathrm{HSI}, \%)=$ liver wet weight $/ \mathrm{W}_{\mathrm{f}} \times 100$

Viscerosomatic index (VSI, \%) $=$ visceral wet weight $/ \mathrm{W}_{\mathrm{f}} \times 100$

Intraperitoneal fat ratio $(\mathrm{IPF}, \%)=$ Intraperitoneal fat wet weight $/ \mathrm{W}_{\mathrm{f}} \times 100$

Condition factor $\left(\mathrm{CF}, \mathrm{g} / \mathrm{cm}^{3}\right)=\mathrm{W}_{\mathrm{f}} /$ final body length ${ }^{3} \times 100$

Apparent digestibility coefficients (ADCs) of lipid (\%)

$=(1-$ (lipid in feces / lipid in diet $) \times($ yttrium in diet $/$ yttrium in feces $)) \times 100$

$W_{i}$ and $W_{f}$ were the initial and final wet body weights, respectively; $W_{D}$ was dry feed intake; $\mathrm{N}_{i}$ and $\mathrm{N}_{\mathrm{f}}$ were the initial and final number of fish, respectively. The Shapiro-Wilk test confirmed normal distribution before statistical analysis. One-way ANOVA followed by Tukey's test was adopted using SPSS 22.0. Significant differences were identified when $P$ $<0.05$. Values were presented as mean \pm SEM of triplicates.

\section{Results}

Growth performance, feed utilization, and body composition

The SPI50 group showed significantly lower WG than the FM group $(P<0.05)$, and an intermediary WG value was found in the SPI50 group group (Table 2). Furthermore, the FM group showed significantly higher FI than SPI25 and SPI50 groups $(P<0.05)$. No remarked differences in FE, CF, HSI, VSI, IPF, and survival were observed among all groups $(P>0.05)$. Moreover, replacing dietary FM with SPI had no significant effect on body compositions including moisture, protein, lipid, and ash contents $(P>0.05)$ (Table 3$)$. 
Table 2 Growth performance and feed utilization of spotted seabass fed experimental diets for 8 weeks.

\begin{tabular}{llll}
\hline \multirow{2}{*}{ Items } & \multicolumn{3}{l}{ Experimental diet treatments } \\
\cline { 2 - 4 } & $\mathrm{FM}$ & $\mathrm{SPI} 25$ & SPI50 \\
\hline $\mathrm{WG}^{1}$ & $960.64 \pm 26.64^{\mathrm{b}}$ & $876.14 \pm 24.91^{\mathrm{ab}}$ & $839.71 \pm 18.42^{\mathrm{a}}$ \\
$\mathrm{FI}^{2}$ & $99.82 \pm 0.67^{\mathrm{b}}$ & $88.66 \pm 1.70^{\mathrm{a}}$ & $88.16 \pm 0.54^{\mathrm{a}}$ \\
$\mathrm{FE}^{3}$ & $0.88 \pm 0.03$ & $0.85 \pm 0.00$ & $0.85 \pm 0.01$ \\
$\mathrm{CF}^{4}$ & $2.04 \pm 0.07$ & $1.92 \pm 0.00$ & $2.05 \pm 0.04$ \\
$\mathrm{HSI}^{5}$ & $1.64 \pm 0.06$ & $1.70 \pm 0.07$ & $1.46 \pm 0.12$ \\
$\mathrm{VSI}^{6}$ & $11.96 \pm 0.44$ & $12.15 \pm 0.44$ & $12.24 \pm 0.47$ \\
$\mathrm{IPF}^{7}$ & $6.37 \pm 0.39$ & $5.85 \pm 0.09$ & $5.94 \pm 0.18$ \\
Survival (\%) & $96.00 \pm 2.31$ & $98.00 \pm 2.00$ & $98.67 \pm 1.33$ \\
\hline
\end{tabular}

Values are mean \pm SEM of triplicate groups. Values in the same row with different superscripts are significantly different $(P<0.05)$.

1 WG: weight gain (\%).

2 FI: feeding intake ( $\mathrm{g} / \mathrm{fish})$.

${ }^{3}$ FE: feed efficiency.

${ }^{4} \mathrm{CF}$ : condition factor $\left(\mathrm{g} / \mathrm{cm}^{3}\right)$.

${ }^{5}$ HSI: hepatosomatic index (\%).

${ }^{6}$ VSI: viscerosomatic index (\%).

7 IPF: intraperitoneal fat ratio (\%).

Table 3 Body compositions (wet weight) of spotted seabass fed experimental diets for 8 weeks.

\begin{tabular}{|c|c|c|c|}
\hline \multirow[t]{2}{*}{ Items } & \multicolumn{3}{|c|}{ Experimental diet treatments } \\
\hline & FM & SPI25 & SPI50 \\
\hline Moisture (\%) & $65.90 \pm 0.75$ & $65.71 \pm 0.42$ & $65.42 \pm 0.42$ \\
\hline Crude protein (\%) & $18.23 \pm 0.09$ & $18.17 \pm 0.14$ & $18.55 \pm 0.22$ \\
\hline Crude lipid (\%) & $12.01 \pm 0.24$ & $12.35 \pm 0.11$ & $12.18 \pm 0.16$ \\
\hline Crude ash (\%) & $4.04 \pm 0.02$ & $3.93 \pm 0.04$ & $4.28 \pm 0.06$ \\
\hline
\end{tabular}

Values are mean \pm SEM of triplicate groups. Values in the same row with different superscripts are significantly different $(P<0.05)$.

\section{Digestive capacity}

Compared with the FM group, the SPI50 group showed markedly lower intestinal trypsin and lipase activities $(P<0.05)$, while the difference did not reach significance in the SPI25 group $(P>0.05)$ (Table 4). There was no significant difference in intestinal amylase activity among all treatments $(P>0.05)$. In addition, ADCs of lipid dramatically decreased with dietary SPI inclusion $(P<0.05)$.

\section{Gut histology}

No inflammatory or degenerative changes were found in the intestine of any experimental group (Figure 1A). The values of villus height, thickness, muscular thickness and perimeter ratio, were markedly decreased in the SPI50 group compared with the FM group $(P<0.05)$, whereas these traits did not differ between FM and SPI25 groups $(P>$ 0.05) (Figure 1B-E). 
Table 4 Intestinal digestive enzyme activities and apparent digestibility coefficients (ADCs) of lipid in spotted seabass fed experimental diets for 8 weeks.

\begin{tabular}{|c|c|c|c|}
\hline \multirow[t]{2}{*}{ Items } & \multicolumn{3}{|c|}{ Experimental diet treatments } \\
\hline & FM & SPI25 & SPI50 \\
\hline Trypsin (U/mgprot) & $370.42 \pm 22.94^{b}$ & $309.63 \pm 26.07^{\mathrm{ab}}$ & $264.64 \pm 17.60^{a}$ \\
\hline Lipase (U/mgprot) & $1.36 \pm 0.03^{b}$ & $1.27 \pm 0.04^{b}$ & $0.90 \pm 0.09^{a}$ \\
\hline Amylase (U/mgprot) & $0.21 \pm 0.03$ & $0.20 \pm 0.01$ & $0.16 \pm 0.02$ \\
\hline ADCs of lipid (\%) & $96.89 \pm 0.14^{c}$ & $93.60 \pm 0.09^{b}$ & $90.66 \pm 0.07^{a}$ \\
\hline
\end{tabular}

Values are mean \pm SEM of triplicate groups. Values in the same row with different superscripts are significantly different $(P<0.05)$.
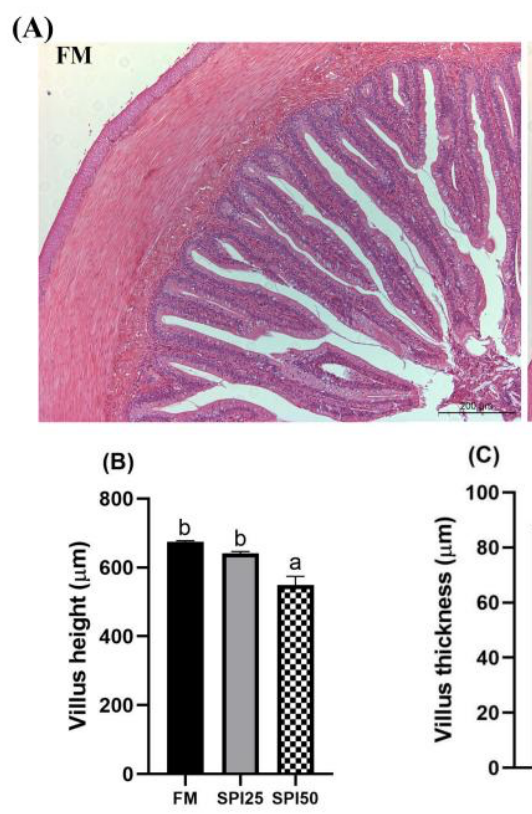

(C)

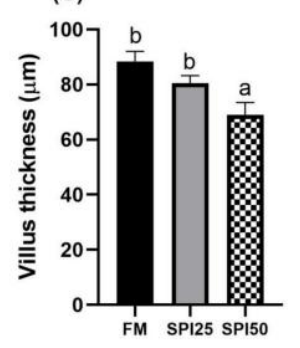

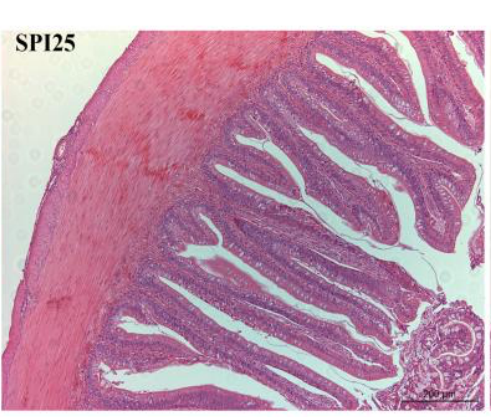

(D)

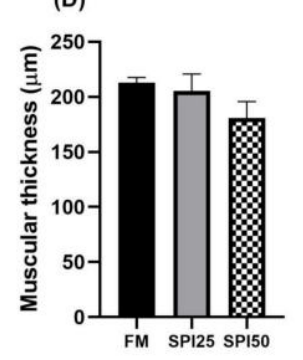

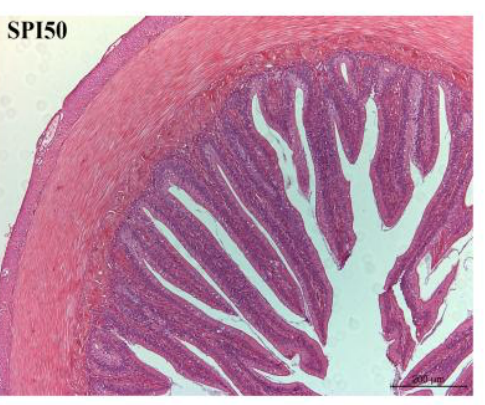

(E)

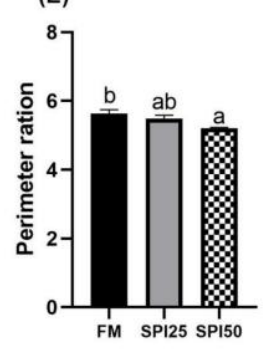

Figure 1 Intestine histology analysis using hematoxylin and eosin (H\&E) staining. (A) Intestinal photomicrographs, scale bar $=200 \mu \mathrm{m}$; (B) Villus height; (C) Villus thickness; (D) Muscular thickness; (E) Perimeter ratio; Bars with different letters are significantly different $(P<0.05)$.

\section{Discussion}

In recent years, several investigations have been conducted on replacing FM with SPI in formulated feeds for fish. Xu et al. (2012) found that up to $57.64 \%$ of dietary FM (basal diet contained $40 \%$ of FM) could be substituted with SPI without significantly affecting the growth and feed conversion rate of Amur sturgeon (Acipenser schrenckii). In contrast, the WG significantly decreased when the replacement level was $75-100 \%$. In the study on Florida pompano (Trachinotus carolinus), SPI could replace $20 \%$ of dietary FM (basal diet contained $31.2 \%$ of FM) without negatively affecting fish growth. In contrast, significantly reduced WG was observed in the diet with higher (40-60\%) FM substitution (Riche and Williams, 2011). A study on hybrid striped bass (Morone chrysops $\times$ M. saxatilis) indicated that $33 \%$ of dietary FM (basal diet contained $10 \%$ of FM) could be readily replaced by SPI (Blaufuss and Trushenski, 2012). Contrary to the above findings, Nepal et al. (2018) found that the growth rate of common carp (Jatropha curcas) increased when $50 \%$ of dietary FM (a basal diet containing $48.4 \%$ of FM) was replaced by SPI. In the present study, substituting $25 \%$ of dietary FM (basal diet had $30 \%$ of FM) with SPI did not markedly affect the WG of spotted seabass. Still, remarkable growth suppression occurred in the SPI50fed group compared with the FM-fed group. The observed discrepancies in the optimum 
inclusion level of SPI in the diet in the above research could be related to the differences in fish species, rearing conditions, feeding strategy, dietary composition, etc. (Zhang et al., 2018).

The use of plant protein sources in aquatic animals was generally limited by three main factors: low palatability, imbalanced essential amino acids (AAs), and excess ANFs contents (Wang et al., 2020a). In the present study, SPI, a refined soy product with lower ANFs contents, acted as an alternative to FM in spotted seabass diets. Generally, FE showed an inverse correlation to the replacement levels of dietary FM in carnivorous fish species (Wang et al., 2020b), and our previous research indicated that replacing $50 \%$ of dietary FM with soybean meal dramatically decreased the FE of spotted seabass. These adverse effects mainly resulted from the ANFs in plant-origin feedstuffs, which were proven to trigger inflammatory responses in the digestive tract (Wang et al., 2021; Zhang et al., 2018). In the present study, similar FE values were detected among all treatments. It might be attributed to the relatively lower types and contents of ANFs in the SPI than other plant protein sources. Lysine and methionine are the two representatives limiting AAs in most plant protein ingredients (Wang et al., 2020b), and the concentrations of the two AAs in all diets have been adjusted to be consistent in this study. However, a dramatically reduced FI was detected in the SPI-fed fish compared with the FM-fed fish, which could be because numerous carnivorous fish, such as spotted seabass, are fishmeal-reliant and less likely to receive the plant-based diet (Liang et al., 2019). Besides, $\beta$-conglycinin, the significant component of SPI, was proven to suppress food intake and gastric emptying (Nishi et al., 2003). In these contexts, the poor growth of the SPI50-fed fish mainly resulted from anorexia-induced FI suppression. Therefore, some attractants could be appropriately added to the diet with high SPI inclusion for future research to improve palatability and food intake in aquatic animals.

The digestive enzymes aided in hydrolyzing macronutrients into absorbable nutrients that can be converted into substrate or energy during a series of physiological processes (Wang et al., 2020b). A previous study on Amur sturgeon (Acipenser schrenckii) showed that intestinal protease, lipase, and amylase activities were dramatically reduced with increasing levels of FM replaced by SPI (Xu et al., 2012). In line with this finding, results obtained from the current study showed that trypsin and lipase activities in the intestine were gradually reduced with increasing dietary SPI levels, resulting in significant when the substitution levels were up to $50 \%$. Besides, we found that lipid digestibility decreased with dietary SPI inclusion, which was consistent with previous findings on common carp (Jatropha curcas) and silvery-black porgy juveniles (Sparidentex hasta) (Nepal et al., 2018; Yaghoubi et al., 2016). These might be due to the SPI-derived indigestible polysaccharides involved in binding action with bile salts, which were proven to inhibit the digestion of diet-derived lipids (Yaghoubi et al., 2016).

The gut is regarded as a core organ involved in contact with ingested food. Therefore, the integrity of the intestinal structure plays a significant role in maintaining the mucosal barrier function (Zeng et al., 2020). Although SPI has been processed to remove most of ANFs, including saponin, isoflavone, phytate, etc., however, the remained antigenic proteins (i.e., $\beta$-conglycinin, glycinin, and bioactive peptides) could also provoke hypersensitivity reactions in the gastrointestinal tract, and even lead to dysfunction of intestine barrier (Peng et al., 2018). Besides, a recent study on mice indicated that dietary SPI versus casein attenuated intestinal immunoglobulin and mucin production (Zeng et al., 2020). Accordingly, when the concentrations of SPI exceed the toleration limitation, it could induce adverse effects on mucosal barrier function in fish, especially carnivorous fish (Yaghoubi et al., 2016). Our previous study showed that substituting $50 \%$ of dietary FM with soybean meal led to intestine inflammation in spotted seabass, which is referred to as soybean meal-induced enteritis (SBMIE) (Zhang et al., 2018).

Conversely, the current study revealed no intestinal inflammatory or degenerative change in any experimental group; the discrepancy might be due to the reduced ANFs contained in the SPI compared with soybean meal. However, the intestine's markedly lower perimeter ratio was detected when SPI replaced $50 \%$ of dietary FM. Meanwhile, the decreased 
perimeter ratio corresponded to the inferior villus height/thickness in SPI50 versus FM group, consistent with the existing study on taimen (Hucho taimen) (Wang et al., 2018). The inferior intestinal morphology combined with the suppressed digestive enzymes could partially account for the poor growth of the SPI50-fed versus FM-fed fish. In addition, similar digestive enzyme activities and morphometric parameters were detected between FM-fed and SPI25-fed groups, indicating that SPI could readily replace an appropriate proportion ( $25 \%$ ) of FM in the spotted seabass diet. That can be further confirmed by the performers of the WG, FE, and body compositions between the FM and SPI25 groups.

\section{Conclusion}

SPI could substitute up to $25 \%$ of dietary FM without significantly affecting the growth, FE, digestive enzyme activity, or intestinal morphology of spotted seabass. Although increasing substitution levels (50\%) of FM led to marked growth inhibition, which could be due to the suppressed FI, reduced digestive enzyme activities, and inferior intestinal morphology.

\section{Acknowledgments}

This work was supported by the Natural Science Foundation of Fujian Province of China (grant number: 2019J01688) and the China Agriculture Research System (grant number: CARS47-14).

\section{References}

AOAC (Association of Official Analytical Chemists), 2002. Official Methods of Analysis of Official Analytical Chemists International, 17th ed. AOAC, Arlington, VA, USA.

Blaufuss, P., Trushenski, J., 2012. Exploring Soy-Derived Alternatives to Fish Meal: Using Soy Protein Concentrate and Soy Protein Isolate in Hybrid Striped Bass Feeds. North American Journal of Aquaculture, 74(1): 8-19. doi:10.1080/15222055.2011.635782

Deng, J., Mai, K., Ai, Q., Zhang, W., Wang, X., Tan, B., Xu, W., Liu, Z., Ma, H., 2009. Interactive effects of dietary cholesterol and protein sources on growth performance and cholesterol metabolism of Japanese flounder (Paralichthys olivaceus). Aquaculture Nutrition, 16(4): 419-429. doi:10.1111/j.1365-2095.2009.00681.x

Dimitroglou, A., Merrifield, D. L., Moate, R., Davies, S. J., Spring, P., Sweetman, J., Bradley, G., 2009. Dietary mannan oligosaccharide supplementation modulates intestinal microbial ecology and improves gut morphology of rainbow trout, Oncorhynchus mykiss (Walbaum). Journal of Animal Science, 87(10): 3226-3234. doi:10.2527/jas.2008-1428

Li, Y., Yang, P., Zhang, Y., Ai, Q., Xu, W., Zhang, W., Zhang, Y., Hu, H., Liu, J., Mai, K., 2017. Effects of dietary glycinin on the growth performance, digestion, intestinal morphology and bacterial community of juvenile turbot, Scophthalmus maximus L. Aquaculture, 479: 125-133. doi: 10.1016/j.aquaculture.2017.05.008

Liang, X., Han, J., Xue, M., Yu, H., Huang, H., Wu, X., Zheng, Y., Qin, Y., Liang, X., 2019. Growth and feed intake regulation responses to anorexia, adaptation and fasting in Japanese seabass, Lateolabrax japonicas when fishmeal is totally replaced by plant protein. Aquaculture, 498: 528-538. doi: 10.1016/j.aquaculture.2018.09.010

Liu, Y., Yang, J., Lei, L., Wang, L., Wang, X., Ma, K., Yang, X., Chen, Z.Y., 2017. $7 \mathrm{~S}$ protein is more effective than total soybean protein isolate in reducing plasma cholesterol. Journal of Functional Foods, 36: 18-26. doi: 10.1016/j.jff.2017.06.039

Naylor, R.L., Hardy, R.W., Buschmann, A.H., Bush, S.R., Cao, L., Klinger, D.H., Little, D.C., Lubchenco, J., Shumway, S.E., Troell, M., 2021. A 20-year retrospective review of global aquaculture. Nature, 591(7851): 551-563. doi:10.1038/s41586-02103308-6

Nepal, S., Kumar, V., Makkar, H.P.S., Stadtlander, T., Romano, N., Becker, K., 2018. Comparative nutritional value of Jatropha curcas protein isolate and soy protein isolate in common carp. Fish Physiology and Biochemistry, 44(1): 143-162. doi:10.1007/s10695017-0420-x

Nishi, T., Hara, H., Tomita, F., 2003. Soybean beta-conglycinin peptone suppresses food intake and gastric emptying by increasing plasma cholecystokinin levels in rats. Journal of Nutrition, 133(2): 352-357. doi: 10.1093/jn/133.2.352 
NRC, 2011. Nutrient Requirements of Fish and Shrimp. National Academy Press, Washington, DC.

Peng, C., Cao, C., He, M., Shu, Y., Tang, X., Wang, Y., Zhang, Y., Xia, X., Li, Y., Wu, J., 2018. Soybean Glycinin- and beta-Conglycinin-Induced Intestinal Damage in Piglets via the p38/JNK/NF-kappa B Signaling Pathway. Journal of Agricultural and Food Chemistry, 66(36): 9534-9541. doi: 10.1021/acs.jafc.8b03641

Riche, M., Williams, T.N., 2011. Fish meal replacement with solvent-extracted soybean meal or soy protein isolate in a practical diet formulation for Florida pompano (Trachinotus carolinus, L.) reared in low salinity. Aquaculture Nutrition, 17(4): 368-379. doi: 10.1111/j.1365-2095.2010.00808.x

Wang, C., Liu, H., Xu, Q., Li, J., Wang, L., Zhao, Z., Yin, J., 2018. Effects of fish meal replacement by soybean protein isolate on digestive physiology of taimen Hucho taimen. Journal of Dalian Ocean University, 33: 607-613. doi: 10.16535 /j.cnki.dlhyxb.2018.05.010

Wang, J., Clark, G., Ju, M., Castillo, S., Gatlin, D.M., 2020a. Effects of replacing menhaden fishmeal with cottonseed flour on growth performance, feed utilization and body composition of juvenile red drum Sciaenops ocellatus. Aquaculture, 523: 735217. doi: 10.1016/j.aquaculture.2020.735217

Wang, X., Yuan, Y., Li, C., Zhou, F., Jin, M., Sun, P., Zhu, T., Ding, X., Zhou, Q., 2020b. Partial substitution of fish meal with soy protein concentrate in commercial diets for juvenile swimming crab, Portunus trituberculatus. Animal Feed Science and Technology, 259: 114290. doi: 10.1016/j.anifeedsci.2019.114290

Wang, Z., Yang, M.Q., Wang, L., Lu, K.L., Song, K., Zhang, C.X., 2021. Bacillus subtilis LCBS1 supplementation and replacement of fish meal with fermented soybean meal in bullfrog (Lithobates catesbeianus) diets: Effects on growth performance, feed digestibility and gut health. Aquaculture, 545: 737217. doi: 10.1016/j.aquaculture.2021.737217

Xu, Q., Wang, C., Zhao, Z., Luo, L., 2012. Effects of Replacement of Fish Meal by Soy Protein Isolate on the Growth, Digestive Enzyme Activity and Serum Biochemical Parameters for Juvenile Amur Sturgeon (Acipenser schrenckii). Asian-Australasian journal of animal sciences, 25(11): 1588-1594. doi:10.5713/ajas.2012.12192

Yaghoubi, M., Mozanzadeh, M.T., Marammazi, J.G., Safari, O., Gisbert, E., 2016. Dietary replacement of fish meal by soy products (soybean meal and isolated soy protein) in silvery-black porgy juveniles (Sparidentex hasta). Aquaculture, 464: 50-59. doi: 10.1016/j.aquaculture.2016.06.002

Zeng, B., Wang, D., Wang, H., Chen, T., Luo, J., Xi, Q., Sun, J., Zhang, Y., 2020. Dietary soy protein isolate attenuates intestinal immunoglobulin and mucin expression in young mice compared with casein. Nutrients, 12: 2739. doi: 10.3390/nu12092739

Zhang, C., Rahimnejad, S., Wang, Y., Lu, K., Song, K., Wang, L., Mai, K., 2018. Substituting fish meal with soybean meal in diets for Japanese seabass (Lateolabrax japonicus): Effects on growth, digestive enzymes activity, gut histology, and expression of gut inflammatory and transporter genes. Aquaculture, 483: 173-182. doi: 10.1016/j.aquaculture.2017.10.029 